\title{
Los Síntomas de Pacientes con Hipertensión Pulmonar de Grupo 1 ó 4 son
Malos Predictores de su Gravedad: La Experiencia de la Red Colombiana de
Hipertensión Pulmonar.
}

Mauricio Orozco-Levi, Melissa Mogollón, Javier Fajardo, Alba Ramírez-Sarmiento, Rafael Conde, Héctor Ortega, Manuel Pacheco, Luis Echeverría, Federico Saaibi, Alejandro Londoño. Servicio de Neumología, Centro para el Cuidado de la Salud Respiratoria, Hospital Internacional de Colombia. Santander, Colombia. Universidad de Santander, Colombia. Universidad Industrial de Santander (UIS), Bucaramanga, Colombia. IPS Respiremos, Pereira, Colombia. Clínica CardioVid, Medellín, Colombia. Fundación Neumológica Colombiana, Bogotá, Colombia.

\section{INTRODUCCIÓN Y OBJETIVO}

La Hipertensión Pulmonar (HP) es un trastorno hemodinámico grave en el cual se han identificado múltiples indicadores de mal pronóstico de los pacientes. En la clínica habitual, los síntomas de disnea, clase funcional y capacidad de ejercicio (test de marcha o cicloergometría) son utilizados, entre otros factores, como indicadores de bajo, medio o alto riesgo de mortalidad a un año. Sin embargo, nuestra percepción clínica dentro de la Red Colombiana de Hipertensión Pulmonar (HAPred.co) sugiere que la gravedad de la enfermedad en grupo 1 y grupo 4 en términos hemodinámicos puede no estarse reflejando de forma lineal con los síntomas reportados por los pacientes en pacientes de la zona andina.

Objetivo: Evaluar la asociación que puede existir entre variables hemodinámicas y consumo de oxígeno pico con los síntomas centrales (disnea) o periféricos (piernas) en pacientes residentes en la zona andina con diagnóstico incidente de HP grupo 1 y grupo 4.

\section{MATERIALES Y MÉTODOS}

Se incluyó en el análisis la información de todos los pacientes identificados en la Red Colombiana de Hipertensión Pulmonar (HAPred.co). Esta es una iniciativa gremial multidisciplinaria y multicéntrica que consolida y analiza la información de pacientes con diagnóstico confirmado hemodinámicamente de HP, con especial énfasis en los Grupos 1 y 4 de la enfermedad. Se realizaron análisis de correlación (lineal y no-lineal) entre las variables funcionales en reposo (presiones, resistencias y gasto cardíaco en cateterismo derecho) y los síntomas en diversas situaciones clínicas.
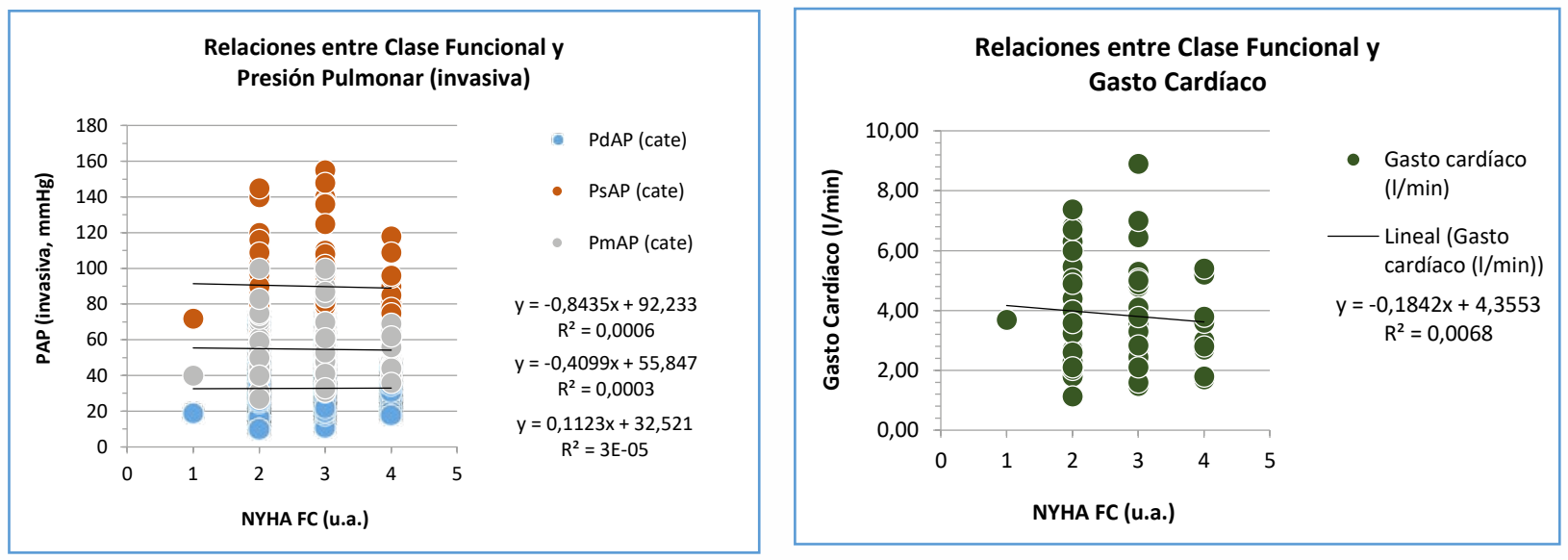

RESULTADOS

Hasta la fecha hemos incluido en el análisis 104 pacientes adultos ( $50 \pm 17$ años, $74 \%$ mujeres), con diagnóstico de HP grupo 1 y grupo 4 . El tiempo reportado de síntomas previos hasta el diagnóstico fue de 29 meses (mediana, 12 meses, 10 pacientes con más de 5 años), Un total de 67 pacientes presentaron diagnóstico de HP grupo 1, los demás grupo 4. El 78\% presentaban una o más comorbilidades. La clase funcional (NYHA) no mostró correlación lineal con la edad, BMI ni variables ecocardiográficas o del cateterismo pulmonar registradas al momento del diagnóstico ni en la última visita de seguimiento $\left(p=n s, r^{2} \leq 0,1\right)$.

\section{CONCLUSIÓN}

En pacientes de la región andina colombiana, la clase funcional no guarda una correlación lineal con la gravedad de las alteraciones hemodinámicas registradas en el cateterismo pulmonar. Estos resultados resaltan la importancia de evaluar de forma objetiva los pacientes con HP del grupo 1 y 4, pues las variables subjetivas (síntomas) en el diagnóstico o seguimiento pueden subestimar drásticamente el grado de deterioro funcional cardíaco.

\section{Subvencionado, en parte, por Grant irrestricto BAYER, 2019}

